
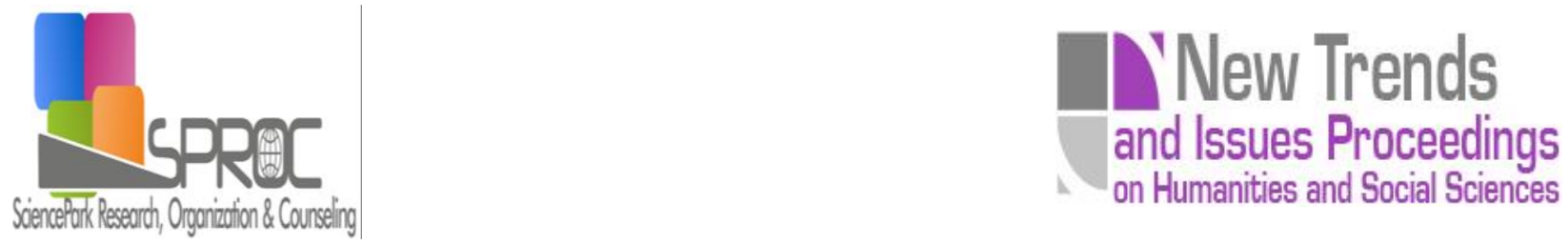

\title{
Investigation of relations among preschool children and their parents' use of technological devices and reading habits (An example kindergarten in the Kirikkale)
}

Damla Pektas ${ }^{\mathrm{a}} *$

Suggested Citation:

Pektas, D

New Trends and Issues Proceedings on Humanities and Social Sciences.

Abstract 
1. Introduction

2. Aim of the study

\section{Methods}

3.1.

3.2. 
3.3.

\section{Results}




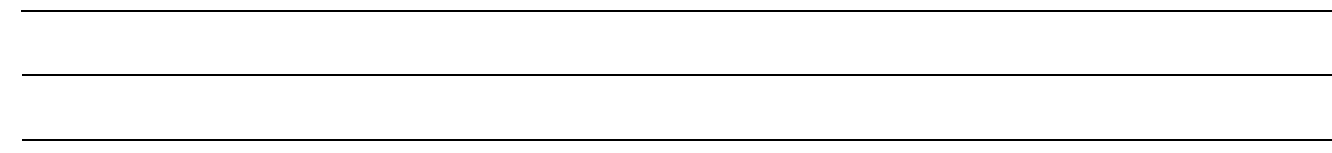


5. Discussion and conclusion 


\section{References}

Hacettepe Universitesi Egitim Fakultesi Dergisi 23

TOJET: The Turkish Online Journal of Educational Technology 4 Newsweek

Medya okuryazarligi ogretim materyali.

Ilkogretim Online 10

Ahi Evran Universitesi Kirsehir Egitim Fakultesi Dergisi 13

Cocuklar icin erken uyarici Cevre

Journal of Educational Technology \& Society 17 
M. Gonen (Editor). Cocuk Edebiyati. Ankara: Egiten Kitap

Young, KS, Yue, XD, Ying, L.(2011). PrevalenceEstimatesandEtiologicModels of Internet Addiction, Internet Addiction: aHandbookand Guide to Evaluation andTreatment, Ed.: KS Young, CN Abreu, Wiley\&Sons, New Jersey 